\title{
Exergetic analysis of regenerative rankine cycle with partial evaporation using zeotropic mixture as working fluid
}

\author{
Kyoung Hoon $\mathrm{Kim}^{\mathrm{a} *}$ \\ ${ }^{a}$ Department of Mechanical Engineering, Kumoh National Institute of Technokogy \\ Daehakro 61, Gumi, Gyeongbuk 39177, Korea
}

\begin{abstract}
The power generation cycle using zeotropic mixture as working fluid has several advantages for recovery of lowgrade finite heat sources. In this paper an exergetic analysis is carried out for regenerative partial-evaporation Rankine cycle with ammonia-water mixture. Based on the first and second laws of thermodynamics, the effects of the important system parameters on the exergetical performance of the system were theoretically investigated. The results showed that the second law efficiency has an optimum value with respect to the fluid quality at expander inlet as well as the ammonia mass fraction.
\end{abstract}

Keywords: ammonia-water mixture, Rankine cycle, partial evaporation, exergy, second- law efficiency

\section{Introduction}

Due to the increasing global demand for energy, it is becoming more and more important to convert efficiently the low-grade heat source into the more useful energy and to find improved technologies for power generation. In the power generation systems for recovery of finite heat sources of low temperature, an important advantage for the use of zeotropic mixtures like binary ammonia-water mixture as working fluid rather than pure working fluids is that heat can be supplied or rejected with varying temperature while maintaining constant pressure. The heat transfer process with variable temperature relieves the mismatch between hot and cold flows in the heat exchangers. The temperature profiles at both sink and source heat exchangers may be optimally adjusted for performance maximization by using the zeotropic mixture [1]-[5].

If the flow rate and temperature of the finite heat source are kept constant, the maximum energy efficiency criterion can lead to an unsuitable choice of the thermodynamic cycle; rather the combination of energy efficiency and amount of recovered heat will lead to the best choice of the cycle [6]. The ammonia-water based Rankine cycle can operate with considerably high exergetic efficiencies even if the source considered is a low temperature and low exergy one. An increase of the net power output decreases the exergetic efficiency while at the same time it increases the surface of the heat exchangers [7]. In the ammonia-water based Rankine cycle for recovery of finite heat source, changes in the concentration of the mixture allow thermodynamic cycles to adapt to fluctuations in renewable energy sources due to the nature of the ammonia-water mixture, which is an important advantage with respect to other working fluids [8].

In the ammonia-water based Rankine cycles with and without regeneration, the lower limit of workable ammonia concentration decreases with increasing turbine inlet pressure. In the regenerative cycle both the thermal and exergy efficiencies can have peaks at the minimum allowable ammonia concentrations in the working range of system operation and are better than the cycle without

\footnotetext{
* Manuscript received August 24, 2017; revised December 1, 2017.

Corresponding author. Tel.: 82-54-478-7292; E-mail address: khkim@kumoh.ac.kr.

doi: $10.12720 /$ sgce.7.1.24-31
} 
regeneration [9]-[10]. Ammonia-water based Rankine cycle can be used for combined cycles using LNG cold energy. There exists an optimal ammonia mass fraction for the maximum exergy efficiency and a decrease in condensation temperature or pinch temperature difference of the heat exchangers leads to an increased net power generation and exergy efficiency of the system [11].

Recently a new organic Rankine cycle with partial evaporation using the zeotropic mixture $\mathrm{R} 245 \mathrm{fa} / \mathrm{R} 227$ ea as working fluid is proposed [12]. It was reported that the heat exchanger economy may become worse but the partial evaporation and zeotropic mixture working fluid can improve the thermodynamic performance and more importantly they can be combined together to further enhance the system. This paper performs an exergetic analysis of a partial evaporation Rankine cycle with regeneration using ammonia-water mixture as a zeotropic working fluid for recovery of low-temperature finite heat source. The effects of system parameters such as ammonia mass fraction and vapor quality at expander inlet on the exergy destruction at the components of the system as well as the second law efficiency are extensively investigated.

\section{System Analysis}

The schematic diagram of the system is illustrated in Fig. 1. In the system, the working fluid with ammonia mass fraction $\mathrm{x}_{\mathrm{b}}$ flows out the condenser as a saturated liquid temperature Tc of state 1 , and is pressurized by the pump to pressure $\mathrm{P}_{\mathrm{H}}$ of state 2 , and preheated in the regenerator to state 3 . The fluid is then further heated with the source fluid to state 4 where the vapor quality reaches a prescribed value of $\beta$. The supplied source fluid is assumed as air at temperature $\mathrm{T}_{\mathrm{H}}$. The fluid then enters the expander and produces mechanical work during the expansion to the condensation pressure of state 5. The working fluid enters then the regenerator and comes out after preheating the working fluid as state 6 , and the cycle is completed.

For the simplicity of the system analysis, some assumptions are made as follows: the heat losses except heat exchangers and pressure variations except the expander and pump are ignored. Isentropic efficiencies of the pump and expander are maintained at constant values $\eta_{P}$ and $\eta_{T}$, respectively. The minimum temperature differences between hot and cold streams in the heat exchangers are operated as the prescribed pinch temperature difference, $\Delta \mathrm{T}_{\mathrm{pp}}$. It means that the flow rate of the working fluid becomes the maximum for a specified supplied source fluid.

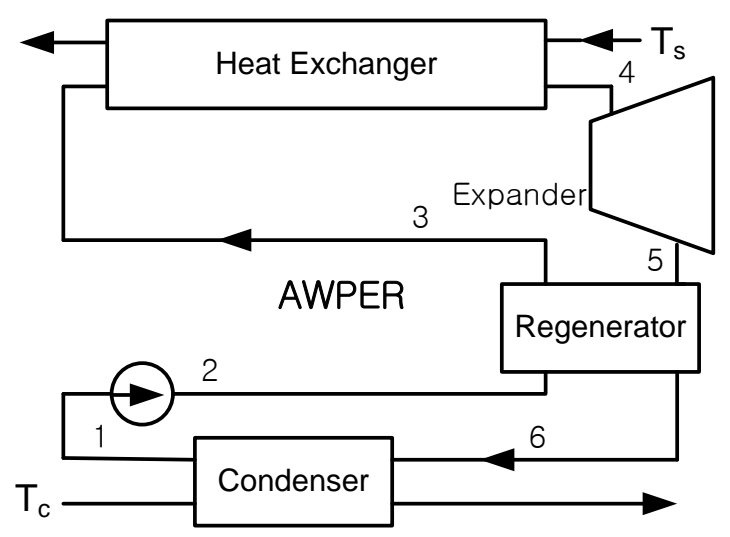

Fig. 1. Schematic diagram of the system.

The heat addition rate Qin and the net power $\mathrm{W}_{\text {net }}$ are obtained as follows:

$$
Q_{\text {in }}=m_{w}\left(h_{4}-h_{3}\right)
$$




$$
W_{\text {net }}=m_{w}\left(h_{4}-h_{3}\right)-m_{w}\left(h_{2}-h_{1}\right)
$$

Here $\mathrm{m}$ is the mass flow rate and $\mathrm{h}$ is the specific enthalpy. The exergy is a property of a stream that is defined as the maximum useful work available when the stream evolves reversibly to reach equilibrium with the environment. The exergy can be evaluated as

$$
E=m\left[h-h_{0}-T_{0}\left(s-s_{0}\right)\right]
$$

where $\mathrm{s}$ is the specific entropy and the subscript 0 represents the reference dead state

The exergy input rate by the source $\mathrm{E}_{\mathrm{s}}$, should be same as the sum of the net power $\mathrm{W}_{\text {net }}$ and the total exergy destruction including exergy losses $\mathrm{d}_{\text {tot }}$, as

$$
E_{s}=W_{n e t}+d_{\text {tot }}
$$

The second-law efficiency $\eta_{\text {II }}$ is defined as the ratio of the net power production to the decrease in the source exergy in the heat exchanger, and the exergy efficiency $\eta_{\mathrm{ex}}$ is defined as the ratio of the net power production to the source exergy $[4,10]$ :

$$
\begin{gathered}
\eta_{I I}=W_{\text {net }} /\left(E_{s}-E_{\text {sout }}\right) \\
\eta_{e x}=W_{\text {net }} / E_{s}
\end{gathered}
$$

The exergy destruction ratio of a component $\mathrm{D}$, as the ratio of the exergy destruction at a component to the exergy input as follows $[4,10]$ :

$$
\begin{aligned}
D_{s o} & =E_{s o} / E_{s} \\
D_{c o} & =E_{c o} / E_{s} \\
D_{h e} & =\left(E_{s}+E_{3}-E_{s o}-E_{4}\right) / E_{s} \\
D_{c d} & =\left(E_{c}+E_{6}-E_{c o}-E_{1}\right) / E_{s} \\
D_{r g} & =\left(E_{5}+E_{2}-E_{6}-E_{3}\right) / E_{s} \\
D_{w n} & =\left(E_{4}+E_{1}-E_{5}-E_{2}-W_{n e t}\right) / E_{s}
\end{aligned}
$$

where subscripts s, c, so, co, he, cd, rg, and wn represent the source, source exhaust, coolant, coolant exhaust, heat exchanger, condenser, refrigerator, and net power, respectively. The sum of the exergy destruction ratios of the system and the exergy efficiency then becomes unity, as follows:

$$
\eta_{e x}+D_{s o}+D_{c o}+D_{h e}+D_{c d}+D_{r g}+D_{w n}=1
$$

The thermodynamic properties of ammonia-water mixture are evaluated using the method of Gibbs free energy which was introduced by $\mathrm{Xu}$ and Goswami [13].

\section{Results and Discussions}

In this work the source fluid is considered as a standard air with $1 \mathrm{~kg} / \mathrm{s}$. The basic data of the system variables are as follows; source temperature $\mathrm{T}_{\mathrm{s}}=160^{\circ} \mathrm{C}$, turbine inlet pressure $\mathrm{P}_{\mathrm{H}}=2 \mathrm{MPa}$, condensation temperature $\mathrm{T}_{\mathrm{L}}=25^{\circ} \mathrm{C}$, coolant temperature $\mathrm{T}_{\mathrm{c}}=15^{\circ} \mathrm{C}$, pinch temperature difference $\Delta \mathrm{T}_{\mathrm{pp}}=5{ }^{\circ} \mathrm{C}$, isentropic pump efficiency $\eta_{p}=0.85$, isentropic expander efficiency $\eta_{t}=0.80$, respectively. The effects of the ammonia mass fraction and the vapor quality on the exergy destruction ratio of source exhaust $\mathrm{D}_{\text {so }}$. There exists a lower limit of allowable ammonia mass fraction for a given quality, due to the imposed 
constraint that the working fluid of binary mixture is supposed to reach the prescribed fluid quality for a specified pressure. This lower limit increases with the fluid quality. The exergy destruction decreases with increasing ammonia mass fraction. It is because the temperature at the pinch point inside the heat exchanger decreases with higher ammonia mass fraction, which consequently lowers the exit temperature. For a given ammonia mass fraction the exergy destruction ratio increases with higher fluid quality. It is because as the fluid quality increases, the exit source temperature increases.

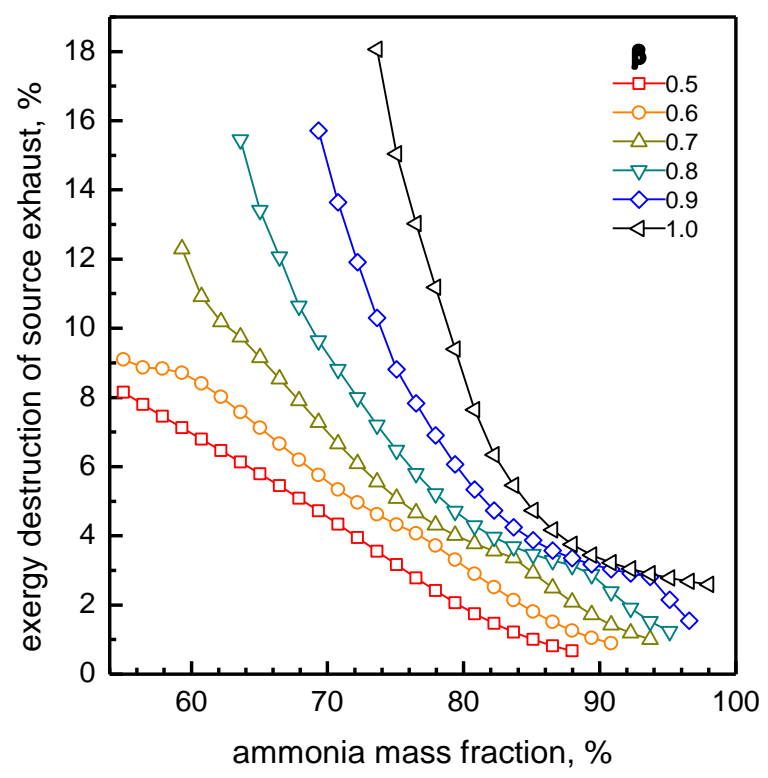

Fig. 2. Effect of ammonia mass fraction on the exergy destruction of source exhaust.

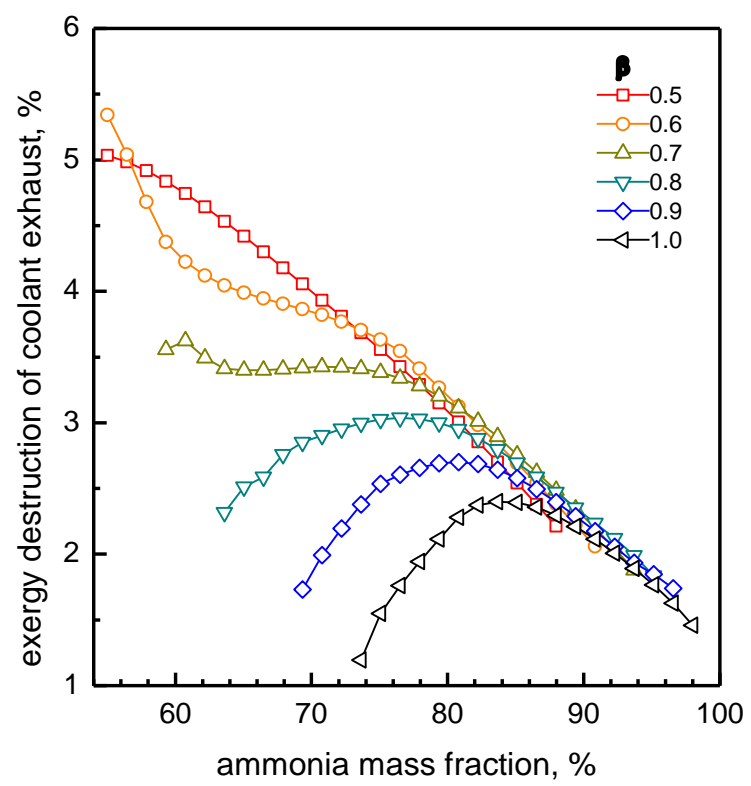

Fig. 3. Effect of ammonia mass fraction on the exergy destruction of coolant exhaust.

Fig. 3 shows the effects of the ammonia mass fraction on the exergy destruction ratio of coolant exhaust $\mathrm{D}_{\mathrm{co}}$ for various vapor qualities. As ammonia mass fraction increases, the exergy destruction ratio 
firstly increases and reaches a local maximum value and then decreases again, so it has a peak value with respect to the ammonia mass fraction. It can be seen from the figure that the ammonia mass fraction for the maximum destruction ratio increases with decrease in the fluid quality. For low fluid qualities, the destruction ratio simply decreases with increasing ammonia mass fraction. When the fluid quality is 0.5 , the exergy destruction ratio decreases almost linearly with increasing ammonia mass fraction. However, the exergy destruction ratio of coolant exhaust is lower than that of the source exhaust.

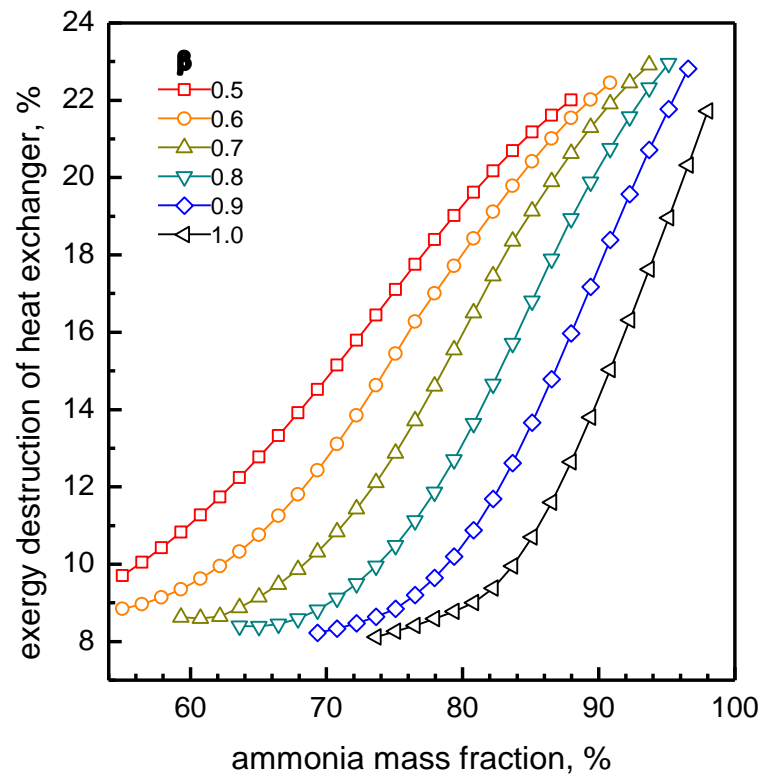

Fig. 4. Effect of ammonia mass fraction on the exergy destruction of heat exchanger.

Fig. 4 shows the effects of the ammonia mass fraction on the exergy destruction ratio of heat exchanger $D_{\text {he }}$ for various vapor qualities. As ammonia mass fraction increases, the exergy destruction ratio increases with increasing ammonia mass fraction. It is because as follows. The heat addition rate is evaluated as the product of the mass flow rate of the working fluid and the specific heat addition in the heat exchanger. The specific heat addition has a local minimum value work with respect to ammonia mass fraction, but the mass flow rate of working fluid in the heat exchanger increases strongly with increase in the ammonia mass fraction, which leads to the increase in the heat transfer and subsequently increase in the exergy destruction ratio with increasing ammonia mass fraction. For a specified ammonia mass fraction, the exergy destruction ratio decreases with increasing fluid quality, due to lower heat transfer in the heat exchanger.

Fig. 5 shows the effects of the ammonia mass fraction on the exergy destruction ratio in the regenerator $D_{\text {rg }}$ for various vapor qualities. The exergy destruction ratio has a peak value with respect to the ammonia mass fraction. It is because as follows. As the ammonia mass fraction increases, the fluid temperature at expander exit decreases which acts as an increasing factor for the heat transfer in the regenerator, but at the same time the phase transition temperature is also lowered which acts as a decreasing factor. Therefore there exist both the increasing and decreasing factors, which leads the tendency [4]. It can be observed from the figure that the maximum exergy destruction ratio and the corresponding ammonia mass fraction increase as the fluid quality increases. 


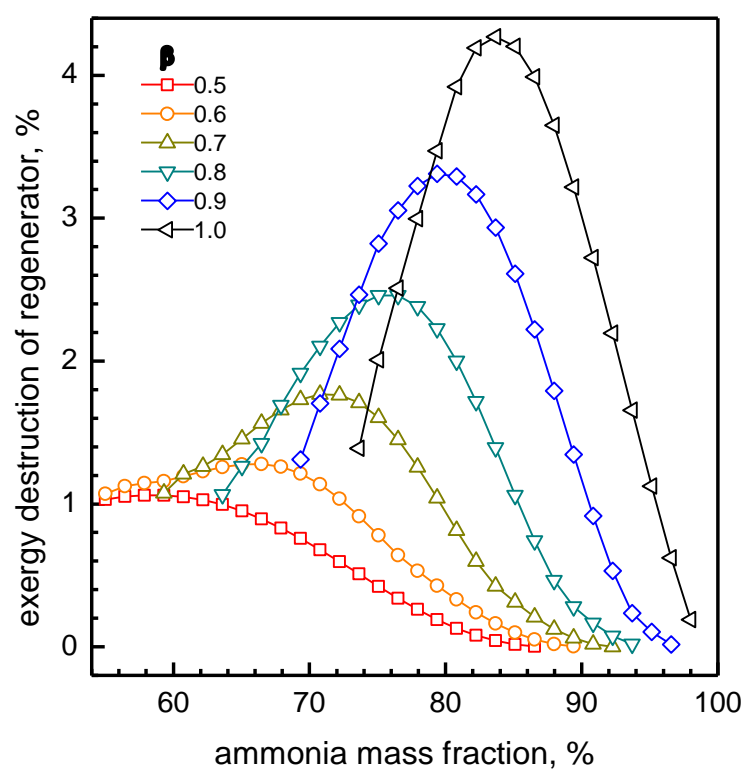

Fig. 5. Effect of ammonia mass fraction on the exergy destruction of regenerator.

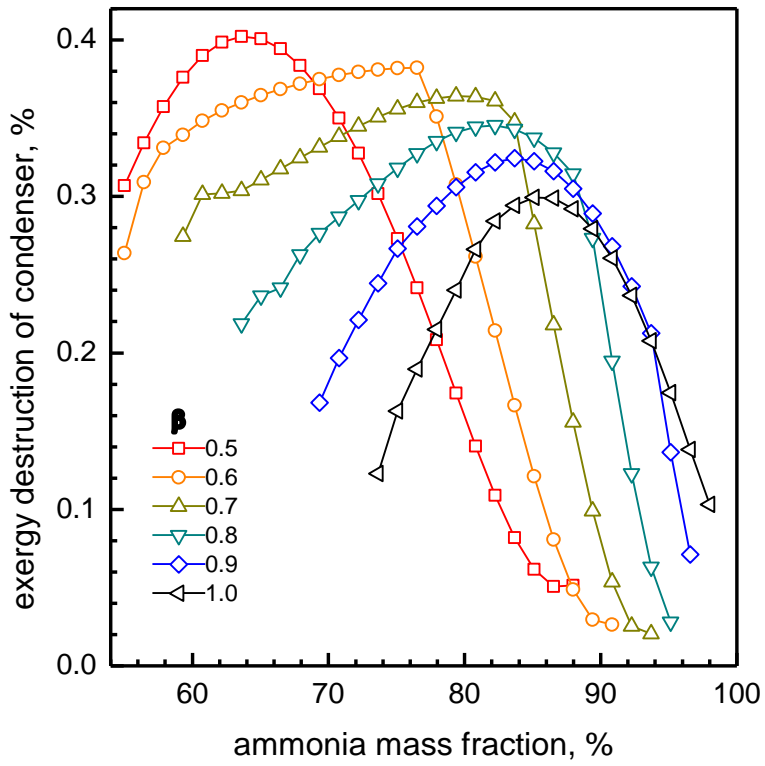

Fig. 6. Effect of ammonia mass fraction on the exergy destruction of condenser.

The effects of the ammonia mass fraction on the exergy destruction ratio in the condenser $\mathrm{D}_{\mathrm{cd}}$ are shown in Fig. 6 for various vapor qualities. It can be seen from the figure that the maximum exergy destruction ratio decreases but the corresponding ammonia mass fraction increases as the fluid quality increases. For a specified ammonia mass fraction, the exergy destruction ratio decreases as the fluid quality increases. However, the exergy destruction ratios in condenser are lower than the heat exchanger, so they are insignificant compared to other exergy destruction ratios.

The effects of the ammonia mass fraction on the second-law efficiency are shown in Fig. 7 for various vapor qualities. It can be seen from the figure that there exists an optimum ammonia mass fraction for the 
local maximum second-law efficiency. It is because as follows. The net power production has a peak value with respect to the ammonia mass fraction, since the specific net work decreases but the mass flow rate of the working fluid increases as the ammonia mass fraction increases. The optimum ammonia mass fraction for the maximum second-law efficiency increases with increasing fluid quality. Exceptionally for very low fluid quality as 0.5 , the second- law efficiency linearly decreases with increasing ammonia mass fraction. It is worth to note that there exists also optimum fluid quality for the maximum second-law efficiency. It can be observed from the figure that the peak value of the second-law efficiency with respect to the ammonia mass fraction becomes the maximum when the fluid quality is 0.8 . For the efficient recovery of finite low-grade heat source, the partial evaporation and the zeotropic mixture working fluid can improve the exergetic performance of the system, and furthermore, they can be combined together to further enhance the system [12].

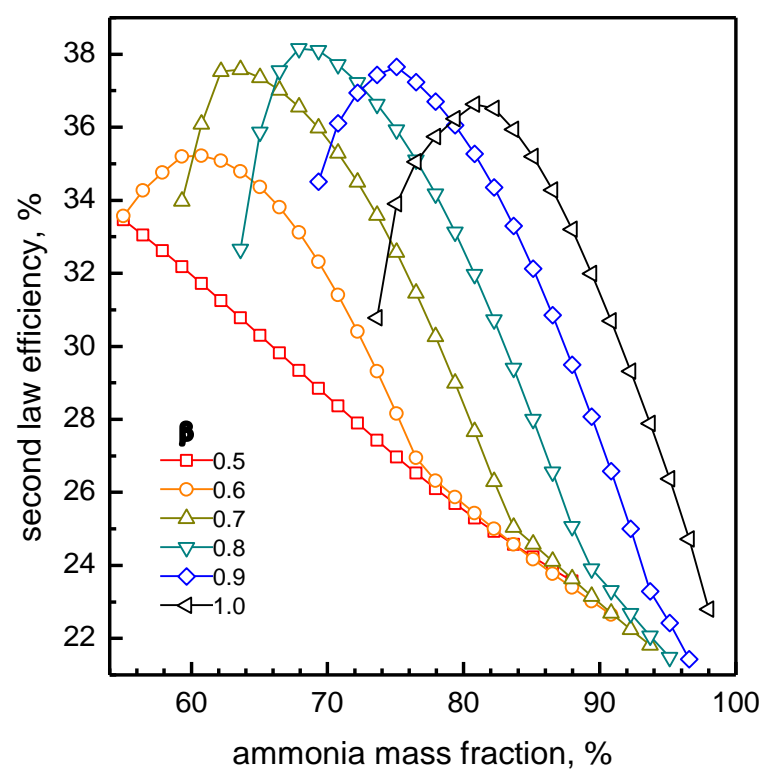

Fig. 7. Effect of ammonia mass fraction on the second-law efficiency.

\section{Conclusion}

This paper presented an exergetical performance analysis of a partial evaporating Rankine cycle using ammonia-water zeotropic mixture as a working fluid for recovery of low-grade finite heat source. The main conclusions from the parametric study of the system are summarized as follows: As the fluid vapor quality at the expander exit increases, the exergy destruction ratios of source exhaust $\left(\mathrm{D}_{\mathrm{so}}\right)$ and regenerator $\left(D_{\mathrm{rg}}\right)$ increase but the exergy destruction ratios of coolant exhaust $\left(D_{\mathrm{co}}\right)$ and heat exchanger $\left(D_{\text {he }}\right)$ decrease. The second-law efficiency of the system has a peak with respect to the fluid vapor quality as well as the ammonia mass fraction. The partial evaporation and the zeotropic mixture working fluid can improve the exergetic performance of the system, and the partial evaporating Rankine cycle using zeotropic mixture as working fluid has a potential to improve recovery of low-grade finite heat source.

\section{Acknowledgements}

This research was supported by Basic Science Research Program through the National Research Foundation of Korea (NRF) funded by the Ministry of Education, Science and Technology (No. 2016935888). 


\section{References}

[1] Ibrahim OM, Klein SA. Absorption power cycle. Energy, 1996; 21: 21-27.

[2] Kim KH, Ko HJ, Kim K. Assessment of pinch point characteristics in heat exchangers and condensers of ammonia-water based power cycles. Applied Energy, 2014; 113: 970-981.

[3] Kim KH, Kim K, Ko HJ. Entropy and Exergy Analysis of a Heat Recovery Vapor Generator for Ammonia-Water Mixtures. Entropy, 2014; 16: 2056-2070.

[4] Kim KH. Comparative exergy analysis of organic flash cycle with and without regeneration using low-grade heat source. Int. J. Exergy, 2017; 23: 330-346.

[5] Sun F, Zhou F, Ikegami Y, Nakagami K, Su X. Energy-exergy analysis and optimization of the solar-boosted Kalina cycle system 11 (KCS-11). Renewable Energy, 2014; 66: 268-279.

[6] Zamfirescu C, Dincer I. Thermodynamic analysis of a novel ammonia-water trilateral Rankine cycle. Thermochimica Acta, 2008; 477: 7-15.

[7] Roy P, Désilets M, Galanis N, Nesreddine H, Cayer E. Thermodynamic analysis of a power cycle using a low-temperature source and a binary $\mathrm{NH}_{3}-\mathrm{H}_{2} \mathrm{O}$ mixture as working fluid. Int. J. Therm. Sci., 2010; 49: 48-58.

[8] Wagar WR, Zamfirescu C, Dincer I. Thermodynamic performance assessment of an ammonia-water Rankine cycle for power and heat production. Energy Convers. Manage., 2010; 51: 2501-2510.

[9] Kim KH, Han CH, Kim K. Effects of ammonia concentration on the thermodynamic performances of ammonia-water based power cycles. Thermochimica Acta, 2012; 530: 7-16.

[10] Kim KH, Han CH, Kim K. Comparative exergy analysis of ammonia-water based Rankine cycles with and without regeneration. Int. J. Exergy, 2013; 12: 344-361.

[11] Kim KH, Kim KC. Thermodynamic performance analysis of a combined power cycle using low grade heat source and LNG cold energy. Applied Thermal Engineering, 2014; 70: 50-60.

[12] Y. Zhou, Zhang F., Yu L. Performance analysis of the partial evaporating organic Rankine cycle (PEORC) using zeotropic mixtures. Energy Conversion and Management, 2016; 129: 89-99.

[13] Xu F, Goswami DY. Thermodynamic properties of ammonia-water mixtures for power cycle. Energy, 1999; $24: 525-536$. 